This item was submitted to Loughborough's Research Repository by the author.

Items in Figshare are protected by copyright, with all rights reserved, unless otherwise indicated.

\title{
In the opponent's shoes: increasing the behavioral validity of attackers' judgments in counterterrorism models
}

PLEASE CITE THE PUBLISHED VERSION

http://dx.doi.org/10.1111/risa.12422

\section{PUBLISHER}

Wiley / @ Society for Risk Analysis

\section{VERSION}

VoR (Version of Record)

\section{PUBLISHER STATEMENT}

This work is made available according to the conditions of the Creative Commons Attribution-NonCommercial 4.0 International (CC BY-NC 4.0) licence. Full details of this licence are available at: http://creativecommons.org/licenses/by-nc/4.0/

\section{LICENCE}

CC BY-NC 4.0

\section{REPOSITORY RECORD}

Bhashyam, Sumitra S., and Gilberto Montibeller. 2019. "In the Opponent's Shoes: Increasing the Behavioral Validity of Attackers' Judgments in Counterterrorism Models". figshare. https://hdl.handle.net/2134/21595. 


\title{
In the Opponent's Shoes: Increasing the Behavioral Validity of Attackers' Judgments in Counterterrorism Models
}

\author{
Sumitra Sri Bhashyam ${ }^{1, *}$ and Gilberto Montibeller ${ }^{2}$
}

\begin{abstract}
A key objective for policymakers and analysts dealing with terrorist threats is trying to predict the actions that malicious agents may take. A recent trend in counterterrorism risk analysis is to model the terrorists' judgments, as these will guide their choices of such actions. The standard assumptions in most of these models are that terrorists are fully rational, following all the normative desiderata required for rational choices, such as having a set of constant and ordered preferences, being able to perform a cost-benefit analysis of their alternatives, among many others. However, are such assumptions reasonable from a behavioral perspective? In this article, we analyze the types of assumptions made across various counterterrorism analytical models that represent malicious agents' judgments and discuss their suitability from a descriptive point of view. We then suggest how some of these assumptions could be modified to describe terrorists' preferences more accurately, by drawing knowledge from the fields of behavioral decision research, politics, philosophy of choice, public choice, and conflict management in terrorism. Such insight, we hope, might help make the assumptions of these models more behaviorally valid for counterterrorism risk analysis.
\end{abstract}

KEY WORDS: Behavioral validity; counterterrorism risk analysis; terrorist decision making; terrorist judgments

\section{INTRODUCTION}

Counterterrorism risk analysis is growing in importance both in terms of research $^{(1,2)}$ and practice. $^{(3,4)}$ The field comprises models that assume terrorist attacks are random events, as well as adversarial models in which the risks are caused by malicious agents who want to take purposeful actions against their enemies. ${ }^{(1,2,5-13)}$

A recent trend in counterterrorism analysis is to model terrorists' judgments, ${ }^{(1,12,14)}$ as these will guide their choice of action, targets, or attack mode. These

${ }^{1}$ Evidera, Metro Building, 6th Floor, 1 Butterwick, London W6 8DL, UK.

${ }^{2}$ School of Business and Economics, Loughborough University, LE11 3TU Loughborough, Leicestershire, UK.

*Address of Correspondence to Dr. Sumitra Sri Bhashyam, Evidera, Metro Building, 6th Floor, 1 Butterwick, London W6 8DL, UK; Sumitra.SriBhashyam@Evidera.com. models are based on several assumptions about how terrorists make decisions and their judgments and, typically, assume that the attacker is fully rational. However, are such assumptions reasonable from a behavioral perspective?

In this article, we analyze the types of assumptions made across various counterterrorism analytical models that represent malicious agents' judgments and discuss their suitability from a behavioral point of view, by drawing knowledge from the fields of behavioral decision analysis, psychology, politics, philosophy of choice, public choice, and conflict management in terrorism. We believe counterterrorism models that represent attackers' judgments could be better informed by empirical findings from these fields. The behavioral evidence we found suggests that terrorists are neither fully rational ("homo economicus") nor irrational-they have instead bounded rationality. ${ }^{(15)}$ We thus make 
several suggestions as to how these assumptions might be adapted so terrorist judgments could be represented in a behaviorally more accurate way in adversarial models, increasing their descriptive validity. For the purpose of our analysis, and in common with most adversarial models, we consider the terrorist organization as a single decisionmaker, which seems to be a reasonable assumption given the military style of hierarchy in this context. ${ }^{(16,17)}$

This article is composed of the following sections. We first provide a short overview of the key methods used in the context of counterterrorism modeling when judgments of terrorists are being represented, the focus of this article, and discuss the main assumptions concerning attackers' judgments that are made in such models. We then discuss the validity of these assumptions in relation to the type of decisionmaker we face, show the considerations to be made when modeling decisions of a terrorist, and suggest changes that can make the models behaviorally more valid. We conclude the article by suggesting some avenues for further research on this theme.

\section{MODELING UNCERTAINTIES AND DECISIONS}

In this section, we review the main approaches to modeling threats caused by terrorism and, subsequently, discuss the assumptions they make regarding the attacker's judgments. These approaches can be broadly classified under two modeling categories: uncertainties (regarding an attacker's decision, capability, and success, and defender's success) and decisions (based on the preferences of the defender and attacker). Probabilistic risk analysis (PRA) relies heavily on modeling uncertainties, using expert elicitation to capture the probabilities associated with them. Game theory (GT), on the other hand, relies on modeling a situation based on the decisions of the players, making the assumptions that both actors are rational. As adversarial risk analysis (ARA) combines both approaches, it needs to make assumptions in both categories.

\subsection{Main Modeling Methods in Counterterrorism Analysis}

PRA in the context of terrorism threats aims to model the situations and decisions from the perspective of the defender's preferences. The attackers' choices are indirectly represented by deriving a ranking of risks, that is, a ranking of the attacks terrorists might potentially employ. ${ }^{5,8,13,14,18,19)}$ The parameters representing risks are subjective judgments elicited by experts. ${ }^{(20,21)}$

A recent trend in modeling terrorism using a decision analytical approach includes the use of decision trees (DTs) and influence diagrams (IDs) to model decisions from the point of view of the attacker. $^{(1,12,14)}$ In this case, the attackers' preferences are estimated in order to try to infer their favored attacks. ${ }^{(1)}$ Multi-attribute utility models (MAUT) $^{(22)}$ have also been proposed in this context, with the definition of terrorists' value models. ${ }^{(12,14)}$

GT has been extensively researched in the context of terrorism in an attempt to capture the interactions between the defender and the attacker, a feature that is difficult to do using PRA. ${ }^{(23-25)}$ In this case, the attacker's consequences are maximized in the context of resource-allocation decisions for the protection of potential targets, ${ }^{(6,23,24,26)}$ and of hostage situations and negotiation analysis. ${ }^{(27-29)}$ For an excellent review on the development in games in the context of terrorism, see Sandler and Siqueira ${ }^{(30)}$ and Kardes. ${ }^{(31)}$

To capture the benefits of both PRA and GT approaches, ARA has recently been suggested. It attempts to capture the risk associated with the attacks, as well as the preferences of both the defender and the attackers. ${ }^{(10,11,32)}$

\subsection{Key Modeling Assumptions in Counterterrorism Analysis Models}

In the context of counterterrorism analysis, PRA analytical tools and other modeling methods, including DTs and GTs, make similar assumptions regarding the attackers' judgments. These can be categorized into three themes described next.

\subsubsection{Assumption 1: Attackers are Rational}

In models that represent terrorists' decisions (such as GT and modeling DTs or IDs from the point of view of the attacker), the issue of the rationality of the decisionmaker arises. Following the standard models of decisions under uncertainty, agents are assumed in these models to be rational decisionmakers who maximize expected utility. ${ }^{(33)}$ The assumption is thus of substantive rationality, in which the behavior is adequate given the desire to achieve a given set of goals. ${ }^{(34)}$ 
Under this premise, and provided that an agent satisfies Savage's axioms of rationality, ${ }^{(35)}$ his/her choices can be represented using expected utility theory (EUT). In this case, mono- or multi-attribute utility theory ${ }^{(22)}$ can be used to model the utility of an agent's choice. This requires the knowledge of the set of objectives the agent is trying to achieve, and in these models, this set is assumed to remain the same throughout time.

\subsubsection{Assumption 2: Attackers are Consequentialists}

Modeling terrorist decision making using GT, ARA, or DT from the terrorists' perspective requires risk analysts to infer which consequences the terrorists are trying to optimize, given the assumption made about substantive rationality. Typically, these consequences are assumed to be costs, damage and propaganda, ${ }^{(6)}$ costs and fatalities, ${ }^{(13)}$ or economic costs. ${ }^{(8)}$

To capture the lack of knowledge about the attacker's preferences, GT has been adapted to account for incomplete information regarding one of the players. In cases where probability distributions from different players are not consistent, multiple utilities can be used in the game. ${ }^{(36)}$ In GT models of asymmetric information, knowledge is updated throughout the game. ${ }^{(28,37)}$

\subsubsection{Assumption 3: Attackers Assess the Situation Objectively}

PRA relies heavily on the availability of intelligence data as well as expert knowledge to assess the parameters involved in the models. These are, for instance, the likelihood of the attacker's success given a particular strike, and the defender's success in preventing it. ${ }^{(1,5,8,9,13)}$ These assessments require the assumption that terrorists view the world objectively, for example, that his/her perception of the probabilities of achieving success or the utility of consequences in reaching a target are not biased. ${ }^{(1)}$

Therefore counterterrorism models make assumptions regarding the rationality of attackers and the way that the latter make their choices, the consequences that they are concerned with, and the probabilities of events that they consider.

Are these three key assumptions realistic from a descriptive perspective? This is what we discuss in the next section.

\section{VALIDITY OF ASSUMPTIONS- IMPLICATIONS FOR MODELING TERRORISM DECISION MAKING}

Counterterrorism models can provide interesting insight as to what a rational player might do, in other words, the solution observed in such models (preferred modes of attack, chosen targets, etc.) arises from a normative view rather than a descriptive one. ${ }^{(1)}$

Extensive behavioral decision research ${ }^{(38-40)}$ has demonstrated that decisionmakers can suffer from various cognitive and motivational biases (see Montibeller and von Winterfeldt for a comprehensive review); ${ }^{(41)}$ these can be induced by external influences, such as the availability of data, but can also be influenced by the state of mind in which the agent finds himself.

In the following subsections, we will thus first discuss the descriptive validity of each key assumption made and, subsequently, suggest how they can be adjusted to increase the behavioral validity of attackers' judgments in counterterrorism modeling.

\subsection{Are Terrorists Rational Decisionmakers?}

Can terrorists be considered as rational decisionmakers, or homo economicus? Terrorists' rationality may be questioned from an economic point of view for several reasons. Their choice of actions may not always be directed to achieving the best outcome in terms of their long-term objectives, that is, political benefits. ${ }^{(42)}$ Furthermore, their chosen targets may not always be those providing the optimal outcome given terrorists' set of objectives. ${ }^{(17,43)}$

Such inconsistencies in decision making have led people to think that terrorists might be irrational in their choice of actions, but research has argued otherwise. ${ }^{(44,45)}$ An important aspect in considering terrorist decisionmakers concerns the type of terrorists we face. Caplan ${ }^{(44)}$ classifies them into three categories (sympathizers, active, and suicidal terrorists), ${ }^{3}$ each one having different attitudes that we discuss in the paragraphs that follow. As different types of terrorists behave slightly differently, knowing which one we are dealing with can give us an indication of the type of rational behavior we can expect from them. We thus can analyze terrorists' rationality using these categories, and consider three standards of

\footnotetext{
${ }^{3}$ Although this classification is well-established in the literature, other more specific terrorist classifications have also been proposed (e.g., Victoroff ${ }^{(45)}$ ).
} 
a rational decisionmaker as a homo economicus: responsiveness to incentives, narrow self-interest, and rational expectations.

\subsubsection{Do Terrorists Respond to Incentives?}

Terrorists are observed to have a negatively sloped demand curve, in other words, riskier tactics are used only if they are more effective. ${ }^{(46,47)}$ The view that terrorists will make tradeoffs between costs and political benefits is supported by empirical evidence. Indeed, their choice of targets, their strategies, and tactics are made using careful evaluations of economic costs, risks, time, and likelihood of success. They have also been seen to be strategic in varying the levels of risk in their "portfolio" of attacks, and choose an offensive strategy that both minimizes resources and maximizes damage and probability of success. $^{(11,48-52)}$

Furthermore, terrorists are versatile in their choices; in other words, they can adapt rapidly to changes in the environment. For instance, they have been seen to change targets quickly if security had been tightened at an original chosen target. ${ }^{(49,51,53)}$

One can argue that suicidal tactics, for instance, can be considered as rational from an economic perspective, as they are quite cost effective in terms of aimed casualties and lives claimed. On average, a Palestinian suicide strike costs USD150; compared to other strikes worldwide it achieves four times as many deaths, and over six times as many in Israel (and 26 times more victims). Furthermore, these strikes are observed mostly when there are no other viable alternatives. ${ }^{(46,47)}$

\subsubsection{Do Terrorists Pursue Narrow Self-Interest?}

Another characteristic of a rational decisionmaker is that he or she is narrowly self-interested, that is, will not engage in actions in which he or she is entirely disinterested. Here the questions relate to the rationality of terrorists for engaging in such costly behavior to gain little or nothing in return. With regard to sympathizers, as Caplan ${ }^{(44)}$ argues, we can safely make the assumption of narrow self-interest. However, in the case of active and suicidal terrorists, this assumption may be less straightforward.

It must be noted that the concept of narrow self-interest has been criticized for its validity, as the evaluation of the act goes beyond the quality of the consequence; rather, a decisionmaker may judge the value of the act by the rules of behavior or the meaning of the act itself. ${ }^{(54)}$ If we thus relaxed this somewhat rigid assumption of narrow self-interest, we could still consider active and suicidal terrorists as rational under this condition. Indeed, interviews of failed suicidal terrorists revealed that their reasons for this sacrifice lie in the cause they serve, and not because of the benefits their family would have received. ${ }^{(55)}$ This also suggests that in the case of suicidal terrorists, the agents value their cause more than their lives, and hence evaluate the consequences of the act according to the cause rather than the consequence to themselves.

\subsubsection{Do Terrorists Have Rational Expectations?}

Another consideration that we can make about terrorists is whether their expectations are rational, that is, when actors make assessments that are realistic and unbiased. In other words, the assessed values should average around the true value of the variable. ${ }^{(33)}$

From this perspective, terrorists' rationality is often questioned because of the beliefs they have. For instance, with Islamic terrorism, the sacrifice of a male suicide bomber would lead him to obtain life in paradise in the company of 72 virgins, so the length of life on earth, compared to that in Paradise, is negligible. ${ }^{(56)}$

Caplan, ${ }^{(44)}$ however, argues that we need to look further, as this argument does not suffice to justify terrorists' rationality. What proof do terrorists have that they would gain such a thing? One proposition suggested is a model of rational irrationality, ${ }^{(44,57)}$ whereby there is an additional and less evident benefit in holding expectations that are evidently against their long-term advantage. Caplan ${ }^{(44)}$ proposes this benefit could be a psychological one, such as giving people a "sense of meaning and personal identity." In this way, if the costs of holding the expectation and the benefits gained from holding these expectations are balanced, one can view this choice as a rational cost-benefit analysis. In other words, "people genuinely embrace irrational beliefs, but remain rational enough to adjust their convictions when the cost of irrationality has a spike."(44, p. 101)

In fact, interviews with failed Palestinian suicidal terrorists provide some psychological insight into what might drive terrorists to sacrifice their lives. ${ }^{(55)}$ In their majority, the failed terrorists had two main traits: susceptibility to social influence and people of authority; and subclinical suicidal characteristics, 
some due to depression or post-traumatic stress syndrome (PTSD). To some extent, these traits can explain their self-destructive acts. However, we note that even though suicide can in fact be a rational response in desperate situations, Merari et al.'s research shows that suicide terrorists may not be driven to suicide by such situations. Their study suggests that although suicidal propensity could be a contributing factor in a significant minority of suicidal terrorists, it appears that such terrorists' motivations and background factors are different from those of ordinary individuals choosing this path. ${ }^{(55)}$

The failed suicidal terrorists were characterized with "a narrow perspective and a constricted experience of reality. They have fewer available resources for planning and implementing deliberate strategies of coping with decision making, and they are more likely to show inept and ineffective ways to cope with ordinary experience of daily living." Furthermore, they are seen to have a dependent and avoidant personality style, which distinguishes them from other types of active terrorists. Such personalities tend to internalize their anger and other emotions, making them more prone to becoming martyrs. Their low self-esteem makes them look for interpersonal relationships, guidance, and care. In contrast, other types of active terrorists were impulsive and emotionally unstable; a personality style more prone to externalizing their emotions. ${ }^{(55)}$

As terrorists operate in groups, $\mathrm{McCormick}^{(43)}$ argues that it might be necessary to view their decisions as the product of organizational decision making to understand their decisions. Although terrorists will, similarly to organizations, use heuristics to evaluate options and outcomes to make their decisions, they do so to the extreme. Research has found a high proportion of terrorists relying on processes of externalization and splitting to a greater extent than normal. ${ }^{(16,58)}$ This is a psychological process affecting behavior that occurs when different mental structures (such as affect, cognition, or perception) are disconnected or split off from consciousness. As such, good and bad traits/aspects of a person/situation are not fully integrated, resulting in a black and white view of an individual/the world. ${ }^{(59-61)}$ Individuals exhibiting personality types such as these tend to have a grandiose and idealized view of themselves, and because of an inability to cope with their weaknesses or flaws, project these hated parts onto others. Similarly, such individuals will then seek outward for the source of issues, for example, search for an enemy to blame. ${ }^{(62)}$ This then distorts their view of themselves, their enemy, and hence the way they will evaluate their options and the resulting outcomes. ${ }^{(43)}$ Next, we suggest some modeling implications in relaxing the standards of rationality for the different types of terrorists.

\subsubsection{Relaxing the Assumption of Rationality}

Although we can safely assume sympathizers behave according to the three standards of a rational decisionmaker, these standards may need to be relaxed for the active and suicidal terrorists, as we suggest below.

3.1.4.1. Consider terrorists' responsiveness to incentives. As discussed in the previous section, the three types of terrorists (sympathizers, active, and suicidal) are considered to respond to incentives. Such behavior can enable risk analysts to better infer the probability of a particular strike being selected (if using DTs from the defender's view), or the attractiveness of a certain strike based on how risky the environment is in a particular location. We can then make the assumption that if in a certain location, a strike $S$ has an efficiency $e$ and a level of risk $r$, it will be preferred to a strike $S^{\prime}$, with efficiency $e^{\prime}$ and a level of risk $r^{\prime}$ if $e>e^{\prime}$ and $r \leq r^{\prime}$.

3.1.4.2. Consider terrorists' self-interest. A rational decisionmaker will not engage in actions in which he/she is entirely disinterested. Although it is safe to assume that sympathizers act according to narrow self-interest principles, the case of active and suicidal terrorists requires some adjustments to be made.

The question in the case of these two latter types of terrorists is what benefits they value in their behavior. Therefore, risk analysts may gain a better understanding of what benefits the attacker might obtain from being an active terrorist. These types of terrorists evaluate the consequences of their act according to the cause they serve rather than the consequences to themselves. One way to reflect this could be by assigning a relatively higher weight to objectives relating to the benefits to the cause resulting from the act than to the cost to the terrorist's life. For instance, as Woo suggested, terrorists might prioritize targets well known in the Middle East, more so if they are generally given media publicity. ${ }^{(63)}$ 
3.1.4.3. Consider terrorists' rational expectations. Active terrorists may be close to adhering to the standard of rational expectation. Even though the malicious agent might choose to have irrational expectations (some that are devoid of evidence, for instance), they would not have such beliefs if they did not gain some sort of benefits from them. Active terrorists are impulsive, emotionally unstable, and are prone to externalize their emotions. ${ }^{(55)}$ Acting out their anger could therefore be a benefit that justifies the cost of engaging in terrorism. Should the costs of having these beliefs become too high, one might expect them to modify their thoughts on the matter. Consequently, this is likely to have an impact on the utility functions as well as the probability of a strike being chosen. Therefore, when describing the utility of active terrorists, modelers could incorporate the benefit gained from externalizing their anger.

Suicidal terrorists, however, do not seem to have rational expectations. ${ }^{(44)}$ Even as the cost rises, some suicidal terrorists will choose to carry on and die rather than reevaluate their beliefs, as observed by the research carried out by Merari et al.,${ }^{(55)}$ who interviewed failed suicidal terrorists. Therefore, it may be useful for risk analysts to have an understanding of the benefits that suicidal terrorists seek from such an act. The psychological benefits can explain suicidal terrorists' willingness to participate in such a selfdestructive act. Their personality type makes them seek care and guidance from stronger personality figures. The benefit they seek when becoming martyrs or victims is the attention they would get from it. The utilities describing what suicidal terrorists may gain from engaging in terrorism would benefit from incorporating this element.

If we, therefore, posit that terrorists can be considered as rational actors who will maximize a utility, the question remains as to what consequences they are trying to maximize, which we discuss next.

\subsection{Do Terrorists Choose Their Actions to Achieve Desired Consequences?}

In this section, we discuss the validity of the dominant view relating to terrorists being politically motivated and having clear objectives. We subsequently present some suggestions regarding the elements to include when modeling the utility of a terrorist. In particular, we suggest that while we might still be able to posit that terrorists are consequentialists, there is evidence that they care about other objectives than only economic or political ones, which affect how the targets are assessed and chosen.

\subsubsection{Do Models Represent the Consequence that Terrorists Really Want to Achieve?}

One assumption made in decision models relates to the ability of decisionmakers to clearly identify and formulate a set of relevant objectives they want to achieve and against which they will evaluate their alternatives. To some extent, it is reasonable to make this assumption in the terrorism context. As mentioned before, terrorists have been seen to choose attacks that offer the best compromise between the operational aspects, such as costs and feasibility, and the benefits gained from the strike. ${ }^{(11,49-52)}$ Furthermore, the psychological study conducted by Merari et al. ${ }^{(55)}$ revealed that the organizers had high coping resources, which enabled them to plan strategically. However, various terrorism models of preferences do not consider all the objectives terrorists might take into account. In addition, we argue that terrorists' preferences may not remain static, which we discuss in Section 3.2.3.

\subsubsection{Do Terrorists Only Seek to Achieve Political Gains?}

As previously discussed, the view that terrorists will make tradeoffs between costs and political benefits is supported by empirical evidence. Targets and strikes are carefully chosen to balance costs, risks, time, and likelihood of success. ${ }^{(11,49-52)}$ For this reason, the dominant view suggests that terrorists are political utility maximizers. ${ }^{(42)}$ Formally, terrorism becomes an attractive form of protest when the political benefits gained by terrorism outweigh the costs, but this does not always seem to be the case. ${ }^{(17)}$

Could it be then that terrorism is a means to achieving something quite different? If some of the terrorists' actions lead us to doubt their rationality because it goes against their political goals, maybe it could be that certain objectives important to terrorism have not been considered.

In addition to the political benefits, Abrahms ${ }^{(17)}$ also points out other benefits to take into account, which are not related to political ones. Indeed, individuals seem to want to belong to a terrorist group for the social aspect of it. This can explain why, even though beneficial to them politically, terrorists are reluctant to participate in peaceful or democratic negotiations. 
Research shows that terrorist organizations appeal to certain kinds of individuals for reasons that are rarely political, and if they are, are of minor importance. As discussed previously, terrorism seems particularly attractive to certain psychological types. ${ }^{(16,45,58)}$ Demographic research also shows that terrorist organizations are mostly composed of individuals not integrated into society for various reasons (from being unmarried to being widowed or unemployed). ${ }^{(17,64-66)}$ Empirical research shows that terrorist members are 10 times more likely to have joined for the social bonds resulting from joining a group than for the ideology of that group. ${ }^{(67)}$ Further evidence shows that the political goals of the organization are rarely known by its members, whether they are foot soldiers or leaders. ${ }^{(68)}$

Therefore, one objective modelers may need to take into account is maximizing the viability of terrorist units. As Abrahms ${ }^{(17)}$ highlights, "terrorist organizations behave more as social solidarity maximizers than as political maximizers." To our knowledge, most counterterrorism decision models do not consider these objectives.

\subsubsection{Do Terrorists' Preferences Remain Static Over Time?}

Individuals are subject to preference change due to two main different sources: endogenous and exogenous. The first one arises when the utility of a consumption depends on the past consumptions, that is, someone's tastes today are influenced by what has been "tasted" previously. ${ }^{(69,70)}$ Sources of exogenous preference change include emotions and visceral factors, which we focus on here. ${ }^{(71)}$

However, counterterrorism analysis usually disregards the temporal dimension of decisions and its effects on preferences. For instance, the design of most decision analytical models, such as that of Rosoff and John, ${ }^{(12)}$ considers the terrorists' values, preferences, and utilities as static; they do not account for potential changes in objectives, or fluctuations in beliefs over time. These changes can occur for various reasons, such as changes in the environment or leadership.

Terrorists' motivations include a reaction to an event. Therefore, an understanding of which objectives terrorists might want to maximize at a given moment requires an appreciation of the state of the environment, and the recent actions from the defender. ${ }^{(71)}$

\subsubsection{Considering Terrorists' Objectives}

We now suggest several aspects that risk analysis may want to consider when modeling terrorists' objectives.

3.2.4.1. Avoid oversimplifying value models. In the evaluation of homeland security decisions, Keeney and von Winterfeldt ${ }^{(7)}$ focus on two main objectives, namely, minimizing both the loss of lives and the costs of the decisions when evaluating policies. This assumes terrorists would only consider a strike based on these two objectives, but is that an adequate representation of how terrorists would evaluate objectives? Evidence suggests that terrorists often have a broader set of objectives to achieve. ${ }^{(17,55,68)}$

A strong assumption in several models, especially in game-theoretical ones, is that objectives are diametrically opposed, which is not necessarily always the case. Each side may have additional objectives that the other side may not consider. For instance, Paté-Cornell and Guikema ${ }^{(32)}$ evaluate various types of strikes based on the symbolism of the attack, the amount of destruction done, and the extent of political destabilization caused. Even as this helps simplify the model and discover interesting solutions, terrorists may consider other objectives, such as causing panic, as we mentioned previously.

3.2.4.2. Extend the objectives against which strikes are evaluated. Based on the variety of attacks used by terrorists, we argue that the objectives generally used in counterterrorism models may not always be sufficient from a descriptive point of view. Consider the case of the Anthrax attack in 2001, for instance. The strike did not cause many casualties (five deaths) relative to other types of attacks. However, a widespread panic, nationwide disrupted mail delivery, as well as costs of USD 1 billion resulted from the strike. ${ }^{(72)}$ More recently, the shutdown of Boston following the marathon bombing is estimated to have cost around USD 1 billion. ${ }^{(73)}$

According to Richardson ${ }^{(68)}$ and Kydd and Walter, ${ }^{(74)}$ the benefits sought by terrorism can be grouped into the following categories: revenge by causing damage in terms of loss of human lives and economic losses; renown by the delivery of a symbolic message through which they want to be recognized as being powerful to promote media coverage and recruitment; and reaction such as achieving a 
Table I. Terrorists' Additional Means-Ends Objectives (Adapted from Abrahms ${ }^{(48)}$ )

\begin{tabular}{|c|c|}
\hline Ends & Means \\
\hline $\begin{array}{l}\text { 1. Prolong their } \\
\text { existence }\end{array}$ & $\begin{array}{l}\text { Using strategies that instead of } \\
\text { promoting policy concessions from } \\
\text { the defender, harden their reluctance } \\
\text { to make them. Lack of success even } \\
\text { for a prolonged length of time does } \\
\text { not make the group give up and } \\
\text { disband. They create new issues to } \\
\text { remain relevant when their political } \\
\text { aims are no longer actual. }\end{array}$ \\
\hline $\begin{array}{l}\text { 2. Ensure their } \\
\text { continued viability }\end{array}$ & $\begin{array}{l}\text { Avoiding to peacefully engage in } \\
\text { democratic processes. }\end{array}$ \\
\hline 3. Avoid disbanding & $\begin{array}{l}\text { Often rejecting negotiated settlements } \\
\text { even though they offer substantial } \\
\text { policy concessions. }\end{array}$ \\
\hline $\begin{array}{l}\text { 4. Guarantee their } \\
\text { survival }\end{array}$ & $\begin{array}{l}\text { Adopting unstable political goals that } \\
\text { can never be completely fulfilled. }\end{array}$ \\
\hline $\begin{array}{l}\text { 5. Avert organization- } \\
\text { threatening } \\
\text { reprisals }\end{array}$ & $\begin{array}{l}\text { Conducting anonymous attacks, even } \\
\text { though they preclude the possibility } \\
\text { of coercing policy concessions. }\end{array}$ \\
\hline $\begin{array}{l}\text { 6. Remain } \\
\text { competitive }\end{array}$ & $\begin{array}{l}\text { Eradicate competitive terrorist } \\
\text { organization with identical ideologies } \\
\text { that competes for members, } \\
\text { regardless of the adverse effect it } \\
\text { might have on their political cause. }\end{array}$ \\
\hline
\end{tabular}

regime change, territorial change, policy change, social control, or maintaining the status quo.

Abrahms ${ }^{(17)}$ suggests that additional benefits to those of political ones need to be taken into account, which are summarized in Table I. Although trying to use tactics to gain a political change, such as engaging in collaborations between organizations to fund their objectives, ${ }^{(74)}$ terrorists' strategies will also include an element that will ensure their existence is continued and justified. This can mean resisting participation in negotiations, or rejecting them. Some of their goals, and means to achieve them, can be detrimental to their cause, such as remaining competitive through destroying competing terrorism groups.

When building adversarial models, risk analysts thus may need to devote more effort to understanding the objectives that drive the terrorism organization if they want to increase the descriptive validity of their models. Some research on what drives terrorism already exists; however, it has been focused on the political goals, and not the social or psychological ones. ${ }^{(42,52,74)}$ While determining what sites to protect against certain types of strikes may be something that is always necessary, the fight against terrorism also needs to try to tackle the issue at its origin: the attractiveness of belonging to a terrorist organization itself. Understanding the latter could provide a basis for devising counterterrorism aimed at depleting terrorist organizations of their members, and slowing their recruitment. Research has found that individuals gain a sense of belonging, success, heroism, and pride. ${ }^{(16,17)}$ Interviews of terrorists by Post et al. ${ }^{(16, \text { p. 194) }}$ have revealed a fusion between the individual and the organization whereby "[i]f the group succeeded, then as an individual they succeeded; if the group failed, they failed. Pride and shame as expressed by the individual were reflections of the group actions, not individual actions, feelings or experiences." Therefore, this suggests that it could be beneficial to direct efforts toward ensuring they gain feelings of shame from their attacks rather than pride from broadcasting their terror efforts.

\subsection{Are Terrorists Normative Decisionmakers?}

Counterterrorism models often make the assumptions that terrorists will decide normatively, that is, as an idealized decisionmaker with infinite mental abilities who is rational and consistent in his/her choices. This excludes the various descriptive elements real-world decisionmakers are usually subject to, such as inconsistent values, the effect of stress, or their inability to keep track of or compute large amounts of information. ${ }^{(75)}$

In DTs and GT in particular, further assumptions are made concerning attackers' utility functions and their probabilities assigned to consequences. ${ }^{(11)}$ But when evaluating the consequences of alternatives and likelihood of outcomes, decisionmakers are subject to two main factors: bounded rationality, ${ }^{(15,34)}$ which may cause violation of some normative axioms, and the effect of emotions. Both of them are discussed in this section.

\subsubsection{Do Terrorists Make Estimates Accurately?}

The uncertainties that terrorists face, and that are most often modeled, are the probabilities of acquiring the material required to perform a strike and the success of such strike. Questions arise as to whether terrorists are able to estimate accurately the probability of being detected and their strike being prevented, as well as the degree to which their strike might be successful. This requires modelers to make further assumptions as to the extent of terrorists' knowledge regarding the defensive capabilities of 
the defenders. However, assuming this was the case, do they have the ability to estimate the required probabilities involved in complex attacks? ${ }^{(1)} \mathrm{We}$ have not found direct evidence about terrorism, but the extensive literature about behavioral biases on the estimations of probability of success, as well as of consequences of alternatives, suggests they probably suffer from the same cognitive and motivational biases as regular decisionmakers do (e.g., overconfidence, anchoring, desirability) ${ }^{(41)}$ and therefore may overestimate the probabilities of success in their acts.

\subsubsection{Do Visceral Factors Influence Terrorist Decision Making?}

In addition to cognitive and motivational biases, the effect of passions or visceral factors (such as anger and fear) might need to be taken into account when considering terrorism decision making. For instance, according to Merari et al., ${ }^{(55)}$ suicide bombers and their organizers are especially prone to the influence of emotions. Because of the strength of these emotions and the state into which they put the individual, they cause a temporary change of behavior. Similarly, $\operatorname{Post}^{(16, p .25)}$ suggests that terrorists "are driven to commit acts of violence as a consequence of psychological forces. In addition, their special psycho-logic is constructed to rationalize acts they are psychologically compelled to commit. Individuals are drawn to the path of terrorism in order to commit acts of violence." His interviews of 35 incarcerated Middle Eastern terrorists revealed that anger and hatred without remorse were often conveyed. ${ }^{(67)}$ Miller ${ }^{(77)}$ also proposes that terrorist motivation can be organized into a three-stage process whereby unacceptable conditions in the environment trigger resentment by the sense of injustice induced, which eventually leads them to find the enemy to be the injustice personified.

Passions, visceral factors, and negative emotions also have an impact on the way agents evaluate probabilities, their risk attitude, and the way they view performances of options. ${ }^{(78)}$ The effects of passions and visceral factors can be categorized into four main streams. Because cognition is temporarily distorted, decisionmakers' evaluation of an outcome's probability or the outcome itself is altered. Furthermore, they may become blind to certain consequences, and look only at consequences made salient by the passions. Decisionmakers' will is altered and weakened such that options with worse outcomes than others are chosen.

These effects also have implications for the way in which modelers evaluate how decisionmakers discount time. Indeed, if the deliberative system evaluates equally long- and short-term consequences, the affective system will put a much greater emphasis on short-term outcomes. ${ }^{(78)}$ Passions and visceral factors influence an agent to behave extremely myopically and to seek immediate rewards, disregarding any detrimental effects, such as the effects observed in addiction. In the context of terrorism, although attackers are known for their long-term strategic planning and patience, ${ }^{(53)}$ myopic behavior can also be observed. Myopic discounting is especially observed in the case of suicide bombers or self-martyrs. ${ }^{(55)}$

Furthermore, there is evidence that negative affective states may influence decision making in various ways, including altering the agent's decision process, or shaping the agent's motives. It has been suggested that distinct states may lead to different influences. ${ }^{(79-84)}$ For instance, research on the impact of sexual arousal and decision making has demonstrated the importance of situational forces on preferences, which are influenced by the emotional state. ${ }^{85,86)}$ Similarly, research suggests that certain emotional states, such as sadness or anxiety, induce biases favoring different types of attributes. Although anxious individuals would favor low-risk/lowreward options, sad individuals are biased in favor of high-risk/high-reward options. ${ }^{(87)}$

\subsubsection{Considering Terrorists' Evaluation of Alternatives and Uncertainties}

We believe there are two main elements having an effect on the assessments of options that are worth considering to increase the behavioral validity of adversarial models, as these can provide some insights into the estimates of how terrorists might score options: the impact that emotions and visceral factors have, as well as the impact of time on terrorists' preferences. Our suggestions are classified into four main categories described below.

\subsubsection{Consider terrorists as myopic decision-} makers. Given the visceral factors terrorists might be experiencing, empirical research supports that they would have the tendency to prioritize short-term objectives rather than long-term ones. ${ }^{(88,89)}$ Consequently, models could heavily discount time (notice 
that organizations on the defender's side might also be myopic in making decisions). ${ }^{(90)}$ In MAUT models, which represent both short- and long-term objectives, a much heavier weight could be allocated to the short-term objectives than one would expect to assign in circumstances where the agents would not be subject to strong emotions.

\subsubsection{Consider that terrorists have an altered} view of objectives. The emotional impact will cause certain objectives to be relatively more important in terrorists' minds, and might result in several other objectives being omitted from a multiobjective function. ${ }^{88}$ The objectives made more salient due to visceral factors are not always rational. In other words, the consequences arising from fulfilling these objectives can be detrimental to the agentas observed in the case of road rage. ${ }^{(89,91)}$ Allocating more weight-or perhaps all weight in some extreme cases-to some of the objectives less geared towards achieving their political gain and more toward the "social aspect" of the terrorist organization may capture this behavior. The social objectives associated with terrorism are summarized in Table I.

Modeling causal relationships can also help in providing an insight into the prioritization of objectives. Certain modeling tools, such as system dynamics, provide the platform to evolve with time or gain an insight into the directions towards which distinct variables might be moving. An attempt at capturing dynamic weights in the context of terrorism was made by Sri Bhashyam and Montibeller. ${ }^{(92)}$ However, GT or DTs would need to be updated accordingly, which could be done using Bayesian updating. ${ }^{(32)}$

3.3.3.3. Consider terrorists' risk attitude. Visceral factors have a strong impact on the assessment of the performance of alternatives, risk attitudes, and the assessments of probabilities. Empirical research shows that emotions have a nonnegligible impact on the judgment of risk. ${ }^{(79,80,82,83,93)}$ Fear in particular influences risk assessments by inflating them, whereas anger does the opposite. In addition, fear induces risk-averse choices, whereas the opposite is observed with anger. ${ }^{(81-83)}$ Admittedly, identifying whether terrorists are attacking under fear or anger might be difficult in practice.

In general, based on the empirical evidence, it is reasonable to assume that terrorists will be affected by anger during the planning of a strike. ${ }^{(55,67,77)}$
Therefore, a more precautionary approach by the risk analyst, at the planning stage of a terrorist attack, would be to assume a risk-seeking behavior of terrorists (instead of the usual linear assumption where, for instance, each death, or financial/media impact is worth the same). However, during the execution phase of a terrorist attack, where the "foot soldiers" are involved in performing the strike, it might be worthwhile for the modeler to consider a risk-averse attitude of attackers, which could be caused by fear

The level of emotion experienced by terrorists could be represented by the steepness of the utility function; the stronger the emotion experienced, the steeper the utility function. Furthermore, the shape of the utility function depends on the type of emotion experienced. A terrorist experiencing fear would have a concave utility function for gains (risk aversion); in contrast, a terrorist experiencing anger would have a convex utility function for gains (risk proneness).

\subsubsection{Consider terrorists' biased estimates.} When incorporating probabilistic assessment from the point of view of the terrorists, risk analysts might consider that decisionmakers are often prone to biased assessments. As highlighted earlier, visceral factors can worsen the effects further, thus the performance of alternatives and risk assessments is bound to be altered.

Hence, terrorists' state of mind could be considered when assessing the performance of certain strikes and their likelihood of success from their point of view. In particular, we suggest that the inferred judgments made by terrorists could be adjusted as follows to reflect the impact of visceral factors. Terrorists under the influence of fear (suicidal terrorists, for example) will tend to be more pessimistic, ${ }^{82,83)}$ hence the probabilities of success of a strike, and the probabilities of the risk they encounter, could be scored lower and higher, respectively. However, terrorists under the influence of anger (sympathizers or active terrorists) will tend to be more optimistic; ${ }^{(82,83)}$ thus, the probabilities of success of a strike, or the probabilities of the risk they encounter, could be scored higher and lower accordingly.

In Table II, we summarize the key modeling considerations we have made throughout the article and how they can be addressed to improve the descriptive validity of attackers' judgments. 
Table II. Modeling Considerations and Implications for Representing Terrorists' Judgments

Modeling Considerations

Responding to incentives

Terrorists and narrow selfishness

Terrorists and rational expectations

Time discounting

Altered view of objectives

Utility functions: risk attitudes
Implications for Modeling Terrorists' Judgments

Findings: Actions taken by the defender can have an impact on the actions the attacker will take. Sympathizers, active, and suicidal terrorists all respond to incentives. This means that if measures are taken to strengthen the security against one type of strike, hence increasing the risk of terrorists being caught, the attractiveness of this strike will diminish. As a result, other strikes will be perceived as more attractive. ${ }^{(49,51,53)}$

Suggestions: This causal variation in the attractiveness of strikes caused by the effect of the defender might be captured by updating the partial utilities of the relevant strikes.

Findings: A rational decisionmaker will not engage in actions in which he or she is disinterested. The question in the case of active and suicidal terrorists is what benefit they value in their behavior, as such terrorists evaluate the consequences of their act according to the cause they serve rather than the consequences to themselves. ${ }^{(44,55)}$

Suggestions: One way to reflect this is by assigning a relatively higher weight to objectives relating to the benefits to the cause resulting from the act than to the weight assigned the terrorist's life. See examples of benefits described in Table I.

Findings: This area concerns whether terrorists' expectations are rational. Active terrorists behave as social solidarity maximizers, rather than political maximizers, and seek to prolong the viability of the units for the social benefits they provide. Suicidal terrorists' behavior can be considered rational if the utility gained from being a martyr in terms of care and attention received is included. ${ }^{(17,44,55,57)}$

Suggestions: In DTs (from the perspective of the terrorists), GT, or ARA models, when representing decisions of active terrorists:

- Include the social benefits involved with terrorism (for instance, those described in Table I).

- Include the psychological benefits of violence; these are means to act out their emotions (anger).

However, when modeling decisions of suicidal terrorists:

- Include the utility gained from taking the status of martyr or victim. These are means to gain attention.

Finding: Terrorists can be considered as myopic decisionmakers. ${ }^{(88,89)}$

Suggestions: Modelers may represent such behavior by:

- Assigning greater relative weight to short-term objectives to reflect that these are prioritized over long-term ones.

- Omitting, in certain extreme cases, long-term objectives, such as gaining political concessions.

Findings: Visceral factors cloud judgment; certain objectives, even self-destructive ones, are prioritized. ${ }^{(88,89,91)}$

Suggestions: Analysts may assign a greater relative weight to objectives contributing to prolong the existence of the terrorist organization.

Findings: Visceral factors affect risk attitudes in the following way: ${ }^{(79-83,93)}$

- Fear renders agents to be risk-averse.

- Anger renders agents to be risk-seeking.

Suggestions:

- When dealing with terrorists prone to fear (for instance, suicidal terrorists), consider their utility function might have a steeper concave shape.

- When dealing with terrorists prone to anger (for instance, active terrorists and terrorist leaders), consider their utility function could have a steeper convex shape. 
Table II. (Continued)

\begin{tabular}{ll}
\hline Modeling Considerations & Implications for Modeling Terrorists' Judgments \\
\hline Biased estimates & Findings: Visceral factors affect risk assessments in the following way: ${ }^{(36,77,78)}$ \\
- & Fear makes agents more pessimistic and hence lowers their perception of being in \\
& control or successful. \\
& Anger makes agents more optimistic as they have a higher perception of being in \\
& control. \\
Suggestions: & \\
- & When dealing with terrorists prone to fear (for instance, suicidal terrorists), analysts \\
& may use a lower perceived probability of success. \\
& When dealing with terrorists prone to anger (for instance, active terrorists and terrorist \\
& leaders) analysts may use a higher perceived probability of success.
\end{tabular}

\section{CONCLUSIONS AND DIRECTIONS FOR FURTHER RESEARCH}

An important trend in counterterrorism analysis is the modeling of attackers' judgments as a way of inferring their choices of targets or modes of operation. The vast majority of models suggested in this field consider the attacker as a fully rational homo economicus.

We argued in this article that it might be also useful to better understand how terrorists' judgments are developed from a descriptive perspective. We analyzed three key assumptions commonly made in counterterrorism risk analytic models: that terrorists are rational decisionmakers, that they are consequentialists, and that they make estimates in an objective way. For each assumption we drew evidence from a wide variety of sources and suggested ways that they could be adjusted in such models.

We hope these suggestions prove useful for enriching adversarial models and for further supporting counterterrorism decision aiding. However, it is an open question whether models that are descriptively valid could provide better predictive power to terrorists' actions than those ones that assume full rationality (a similar debate has been raging in economics for decades without a definitive conclusion).

In addition, we recognize that many of the suggestions made here are tentative and need further development. Furthermore, the evidence we used, despite our best efforts, was mainly from indirect sources, given the inherent difficulties in getting access to the enemy. In addition, similarly to most papers in adversarial risk analysis, we assumed that the terrorist organization is an individual decision- maker, but recognize that more complex organizational relationships exist in practice.

There are several interesting directions of research in this field, three of which we now suggest. First, the development of protocols for eliciting those descriptive parameters required in counterterrorism risk models from counterterrorist experts. This is not a trivial task, as experts would need to place themselves in the "opponent's shoes." Second, the comparison of results between models that employ a fully rational model against those that are behaviorally valid, assessing to which extent they differ and their predictive power, is needed. Third, a behavioral decision research agenda for counterterrorism analysis would be welcome, which could provide a better understanding of the cognitive and motivational biases affecting terrorists and, in particular, of the role of emotions on their decision making.

Concluding, we hope that this article helps in pointing out directions that can make counterterrorism models represent in a more accurate way the judgments of attackers. The increase in behavioral validity would provide richer results and, hopefully, models with better predictive power.

\section{ACKNOWLEDGMENTS}

The authors thank Barbara Fasolo and Gregory Parnell for their review of this work and their insightful comments and suggestions. Furthermore, we thank the two anonymous reviewers and the guest editor Jun Zhuang for their thorough review and constructive comments that helped improve our research and article. Gilberto Montibeller thanks the 
participants of the Create GTHB 2014 Symposium, at the University of Southern California, for their suggestions, in particular Richard John, Milind Tambe, and Heather Rosoff. The article's authors are solely responsible for all opinions, and any eventual omission or mistake.

\section{REFERENCES}

1. Ezell BC, Bennett SP, von Winterfeldt D, Sokolowski J, Collins AJ. Probabilistic risk analysis and terrorism risk. Risk Analysis, 2010; 30(4):575-589.

2. Kardes E, Hall R. Survey of literature on strategic decision making in the presence of adversaries. Unpublished research reports. Available at: http://research. create.usc.edu/nonpublished_reports/115, Accessed Mar 15, 2005.

3. NRC. Committee to Review the Department of Homeland Security's Approach to Risk Analysis. Washington, DC: National Academies Press, 2010.

4. NRC. Department of Homeland Security Bioterrorism Risk Assessment: A Call for Change. Washington, DC: National Academies Press, 2008.

5. Bakir NO. A decision tree model for evaluating countermeasures to secure cargo at United States southwestern ports of entry. Decision Analysis, 2008; 5(4):230-248.

6. Bier V, Oliveros S, Samuelson L. Choosing what to protect: Strategic defensive allocation against an unknown attacker. Journal of Public Economic Theory, 2007; 9(4):563-587.

7. Keeney RL, von Winterfeldt D. A value model for evaluating homeland security decisions. Risk Analysis, 2011;31:14701487.

8. Merrick J, McLay LA. Is screening cargo containers for smuggled nuclear threats worthwhile? Decision Analysis, 2010; 7(2):155-171.

9. Merrick J, Parnell GS. A comparative analysis of PRA and intelligent adversary methods for counterterrorism risk management. Risk Analysis, 2011; 31(9):1488-1510.

10. Parnell GS, Smith CM, Moxley FI. Intelligent adversary risk analysis: A bioterrorism risk management model. Risk Analysis, 2010; 30(1):32-48.

11. Rios J, Rios Insua D. Adversarial risk analysis for counterterrorism modeling. Risk Analysis, 2012; 32(5):894-915.

12. Rosoff H, John R. Decision analysis by proxy for the rational terrorist. Quantitative Risk Analysis for Security Applications (QRASA). IJCAI Pasadena, CA: Quantitative risk analysis for security applications workshop (QRASA) held in conjunction with the International Joint Conference on AI, 2009. Available at: http://teamcore.usc.edu/QRASA09/SubmissionsFinal/Paper_4.pdf, Accessed Aug 12, 2013.

13. Von Winterfeldt D, O'Sullivan TM. Should we protect commercial airplanes against surface-to-air missile attacks by terrorists? Decision Analysis, 2006; 3(2):63-75.

14. Keeney RL. Modeling values for anti-terrorism analysis. Risk Analysis, 2007; 27(3):585-596.

15. Simon HA. Models of Bounded Rationality: Empirically Grounded Economic Reason. Cambridge, MA: MIT Press, 1982.

16. Post JM. Terrorist psycho-logic: Terrorist behavior as a product of psychological forces. In Reich W (ed). Origins of Terrorism: Psychologies, Ideologies, Theologies, States of Mind. Cambridge, NY: Woodrow Wilson Center Press, 1998.

17. Abrahms M. What terrorists really want: Terrorist motives and counterterrorism strategy. International Security, 2008; 32(4):78-105.
18. Pinker EJ. An analysis of short-term responses to threats of terrorism. Management Science, 2007; 53(6):865-880.

19. Bakir NO, von Winterfeldt $\mathrm{D}$. Is better nuclear weapon detection capability justified? Journal of Homeland Security and Emergency Management, 2011; 8(1):1-18.

20. Willis HH, Corporation R. Estimating Terrorism Risk. Santa Monica, CA: Rand Corporation, 2005.

21. Willis HH. Guiding resource allocations based on terrorism risk. Risk Analysis. 2007; 27(3):597-606.

22. Keeney RL, Raiffa H. Decisions with Multiple Objectives. Cambridge, MA: Cambridge University Press, 1993.

23. Wilson GD, Olwell DH (eds). Game Theory in an Age of Terrorism: How Can Statisticians Contribute. Statistical Methods in Counterterrorism. New York: Springer, 2006.

24. Zhuang J, Bier V. Balancing terrorism and natural disastersDefensive strategy with endogenous attacker effort. Operations Research, 2007; 55(5):976-991.

25. Hausken K, Zhuang J. Governments' and terrorists' defense and attack in a T-period game. Decision Analysis, 2011; $8(1): 46-70$.

26. Major JA. Advanced techniques for modeling terrorism risk. Journal of Risk Finance, 2002; 4(1):15-24.

27. Atkinson R. Project management: cost, time and quality, two best guesses and a phenomenon, its time to accept other success criteria. International Journal of Project Management, 1999; 17(6):337-342.

28. Lapan HE, Sandler T. To bargain or not to bargain: That is the question. American Economic Review, 1988; 78(2):16-21.

29. Corsi JR. Terrorism as a desperate game: Fear, bargaining, and communication in terrorist event. Journal of Conflict Resolution, 1981; 25(1):47-85.

30. Sandler T, Siqueira K. Games and terrorism recent developments. Simulation \& Gaming, 2009; 40(2):164-192.

31. Kardes E. Robust Stochastic games and applications to counter-terrorism strategies, 2005. Available from: http://www.usc.edu/dept/create/assets/001/50803.pdf, Accessed Aug 18, 2009.

32. Paté-Cornell ME, Guikema S. Probabilistic modeling of terrorist threats: A systems analysis approach to setting priorities among countermeasures. Military Operations Research, 2002; 7(4):5-23.

33. Sheffrin SM. Rational Expectations, 2nd ed. Cambridge, UK: Cambridge University Press, 1996.

34. Simon HA. Rationality in psychology and economics. Journal of Business, 1986;59(4):S209-S224.

35. North DW. A tutorial introduction to decision theory. IEEE Trans Syst Sci Cybern, 1968; 4(3):200-210.

36. Harsanyi JC. Games with incomplete information played by "Bayesian" players, I-III: Part I. The basic model. Management Science, 2004; 50(12 Suppl):1804-1817.

37. Arce DG, Sandler T. Terrorist signalling and the value of intelligence. British J Polit Sci, 2007; 37(4):573-586.

38. Bazerman MH. Judgment in Managerial Decision Making, 6th ed. Hoboken, NJ: John Wiley \& Sons, 2005.

39. Kahneman D, Slovic P, Tversky A. Judgment Under: Heuristics and Biases. Cambridge, NY: Cambridge University Press, 1982.

40. Tversky A, Kahneman D. The framing of decisions and the psychology of choice. Science, 1981; 211(4481):453-458.

41. Montibeller G, and von Winterfeldt D. Cognitive and motivational biases in decision and risk analysis. Risk Analysis, 2015, doi: 10.1111/risa.12360.

42. Keeney G, von Winterfeldt D. Identifying and structuring the objectives of terrorists. Risk Analysis, 2010; 30(12):18031816.

43. McCormick GH. Terrorist decision making. Annual Review of Political Science, 2003; 6:473-507.

44. Caplan B. Terrorism: The relevance of the rational choice model. Public Choice, 2006; 128(1):91-107. 
45. Victoroff J. The mind of the terrorist: A review and critique of psychological approaches. Journal of Conflict Resolution, 2005; 49(1):3-42.

46. Hoffman B, McCormick GH. Terrorism, signaling, and suicide attack. Studies in Conflict \& Terrorism, 2004; 27(4):243-281.

47. Berman E, Laitin D. Hard targets: Theory and evidence on suicide attacks. Report No.: 11740. Cambridge, MA: National Bureau of Economic Research, Inc., 2005. Available at: http://ideas.repec.org/p/nbr/nberwo/11740.html, Accessed Jan $16,2013$.

48. Abrahms M. Are terrorists really rational? The Palestinian example. Orbis, 2004; 48(3):533-549.

49. Cordes B, Hoffman B, Jenkins BM, Kellen K, Moran S, Sater W. Trends in international terrorism, 1982 and 1983. Santa Monica, CA: Rand Corporation, 1984. Available at: http://www.dtic.mil/cgi-bin/GetTRDoc?AD= ADA483957\&Location $=\mathrm{U} 2 \&$ doc $=$ GetTRDoc.pdf, Accessed Mar 15, 2010.

50. Landes WM. An economic study of U.S. aircraft hijacking, 1961-1976. Journal of Law and Economics, 1978; 21(1):1-31.

51. Mickolus EF. Transnational Terrorism: A Chronology of Events, 1968-1979. Westport, CT: Greenwood Publishing Group, 1980.

52. Pape RA. The strategic logic of suicide terrorism. American Political Science Review, 2003; 97(3):343-361.

53. Woo G. Terrorism risk. Pp. 1-17 in Voeller JG (ed). Wiley Handbook of Science and Technology for Homeland Security. London, UK: Wiley, 2006.

54. Sen AK. Rational fools: A critique of the behavioral foundations of economic theory. Philosophy \& Public Affairs, 1977; 6(4):317-344.

55. Merari A, Diamant I, Bibi A, Broshi Y, Zakin G. Personality characteristics of "self martyrs"/"suicide bombers" and organizers of suicide attacks. Terrorism and Political Violence, 2009; 22(1):87-101.

56. Oliver AM, Steinberg PF. The Road to Martyrs' Square: A Journey into the World of the Suicide Bomber. New York: Oxford University Press US, 2006.

57. Caplan B. Rational ignorance versus rational irrationality. Kyklos, 2001; 54(1):3-26.

58. Mahan S, Mahan S, Sue G, Griset PL. Terrorism in Perspective. London: SAGE Publications, 2012. 457 p.

59. Hinshelwood RD. The social relocation of personal identity as shown by psychoanalytic observations of splitting, projection, and introjection. Philosophy, Psychiatry, \& Psychology, 1995; 2(3):185-204.

60. Maras M-H. Counterterrorism. Burlington, MA: Jones \& Bartlett Publishers, 2012.

61. Post JM. Notes on a psychodynamic theory of terrorist behavior. Terrorism, 1984; 7(2):241-256.

62. Whittaker DJ. The Terrorism Reader, 4th ed. Oxon, UK: Routledge, 2012.

63. Woo G. Joint mitigation of earthquake and terrorism risk. Proceedings of the Earthquake Engineering Research Institute. San Fransisco, CA, 2006.

64. Campbell AC, Philip E., Campbell A, Converse PE, Seeman M, editors. Alienation and Engagement. The Human Meaning of Social Change. New York: Russell Sage Foundation.

65. Roy O. Terrorism and deculturation. Pp. 159-166 in Richardson L (ed). The Roots of Terrorism. New York: Routledge, 2006.

66. Richardson L. The Roots of Terrorism. New York: Routledge, 2006.

67. Post JM, Sprinzak E, Denny LM. The terrorists in their own words: Interviews with thirty-five incarcerated Middle Eastern Terrorists. Terrorism and Political Violence, 2003; 15:171184.
68. Richardson L. What Terrorists Want: Understanding the Terrorist Threat. London, UK: John Murray, 2007.

69. Hammond PJ. Changing tastes and coherent dynamic choice. Review of Economic Studies, 1976; 43(1):159-173.

70. Loewenstein G, Read D, Baumeister RF. Time and Decision: Economic and Psychological Perspectives on Intertemporal Choice. New York: Russell Sage Foundation Publications, 2003.

71. Loewenstein G, Angner E. Predicting and indulging changing preferences. Pp. 114-143 in Loewenstein G, Read D, Baumeister RF (eds). Time and Decision: Economic and Psychological Perspectives on Intertemporal Choice. New York: Russell Sage Foundation Publications, 2003.

72. Cordesman AH. The Challenge of Biological Terrorism. Washington, DC: Center for Strategic \& International Studies, 2005.

73. Plummer B. The entire city of Boston has shut down. How much will this cost? Washington Post, 2013. Available at: http://www.washingtonpost.com/blogs/wonkblog/ wp/2013/04/19/the-entire-city-of-boston-has-shut-down-howmuch-will-this-cost/, Accessed May 17, 2013.

74. Kydd AH, Walter BF. The strategies of terrorism. International Security, 2006; 31(1):49-80.

75. Bell DE, Raiffa H, Tversky A. Decision Making: Descriptive, Normative, and Prescriptive Interactions. Cambridge University Press, 1988.

76. Elster J. Ulysses Unbound. Cambridge, UK: Cambridge University Press, 2000.

77. Miller L. The terrorist mind. I. A psychological and political analysis. International Journal of Offender Therapy and Comparative Criminology, 2006; 50(2):121-138.

78. Loewenstein G, O'Donoghue T. The heat of the moment: Modeling interactions between affect and deliberation. Working paper, Carnegie Mellon University, Pittsburgh, 2007. Available at: http://www.arts.cornell.edu/ econ/edo1/heat.pdf, Accessed Aug 15, 2014.

79. Isen AM, Patrick R. The effect of positive feelings on risk taking: When the chips are down. Organizational Behavior and Human Performance, 1983; 31(2):194-202.

80. Isen AM, Geva N. The influence of positive affect on acceptable level of risk: The person with a large canoe has a large worry. Organizational Behavior and Human Decision Processes, 1987; 39(2):145-154.

81. Wright WF, Bower GH. Mood effects on subjective probability assessment. Organizational Behavior and Human Decision Processes, 1992; 52(2):276-291.

82. Lerner JS, Keltner D. Beyond valence: Toward a model of emotion-specific influences on judgement and choice. Cogn Emotion, 2000; 14(4):473-493.

83. Lerner JS, Keltner D. Fear, anger, and risk. J Personal Social Psychol, 2001; 81(1):146-159.

84. Loewenstein G, Lerner JS. The role of affect in decision making. Pp. 619-642 in Davidson RJ, Scherer KR, Goldsmith HH (eds). Handbook of Affective Science. Oxford, UK: Oxford University Press, 2003.

85. Loewenstein G, Nagin D, Paternoster R. The effect of sexual arousal on expectations of sexual forcefulness. Journal of Research in Crime and Delinquency, 1997; 34(4):443-473.

86. Ariely D, Loewenstein G. The heat of the moment: The effect of sexual arousal on sexual decision making. J Behav Decis Making, 2006; 19(2):87-98.

87. Raghunathan R, Pham MT. All negative moods are not equal: Motivational influences of anxiety and sadness on decision making. Organizational Behavior and Human Decision Processes, 1999; 79(1):56-77.

88. Lerner JS, Tiedens LZ. Portrait of the angry decision maker: How appraisal tendencies shape anger's influence on 
cognition. Journal of Behavioral Decision Making, 2006; 19(2):115-137.

89. Loewenstein G. Out of control: Visceral influences on behavior. Organizational Behavior and Human Decision Processes, 1996; 65(3):272-292.

90. Zhuang J, Bier VM, Gupta A. Subsidies in interdependent security with heterogeneous discount rates. Engineering Economist, 2007; 52(1):1-19.
91. Loewenstein G. Emotions in economic theory and economic behavior. American Economic Review, 2000; 90(2): 426-432.

92. Sri Bhashyam S, Montibeller G. Modeling state-dependent priorities of malicious agents. Decision Analysis, 2012; $9(2): 172-185$.

93. Loewenstein G, Weber EU, Hsee CK, Welch N. Risk as feelings. Psychological Bulletin, 2001; 127(2):267-286. 